\title{
Wicked Problems through a New Lens: Combining Active Learning Strategies for Solutions-Oriented Teaching
}

\author{
Katherine E. Bishop-Williams \\ University of Guelph \\ University of Waterloo \\ kbishop@,uoguelph.ca
}

\begin{abstract}
Wicked problems are large, complex problems involving multiple perspectives that present substantial future challenges. These challenges can be overwhelming for learners and pose difficulties in teaching for instructors. Herein a solutions-oriented teaching strategy that amalgamates proven active learning strategies is presented along with a step-by-step guide and materials list. Evidence of student learning is provided. This strategy provides students the opportunity to view complex, wicked problems from multiple perspectives and to visualize their role in future solutions.
\end{abstract}

Keywords: wicked problems, active learning, solutions-oriented

Teaching learners about "wicked problems" (Waltner-Toews, 2017) can position them to feel that the problems they face are insurmountable and impossible to solve. Wicked problems are complex issues involving many stakeholders and multiple perspectives, and often have incomplete problem definitions (Waltner-Toews, 2017). Climate change and health both present wicked problems, and together present one of the greatest challenges (Costello et al., 2009) and opportunities (Watts et al., 2015) of the twenty-first century.

As educators, it is critical to prepare learners to tackle these complex problems. Indeed, it may be the most important role of today's educators. However, limited research exists to inform educators of the best ways to teach about these problems, and to prepare students for these tasks. Teaching students about wicked problems (such as climate change) can have a negative impact on student mental health as existential concerns about humans and the environment can induce anxiety and depression (Maxwell \& Blashki, 2016). Thus, to consider student needs and student mental health while simultaneously educating future leaders and global-citizens, educators should engage in solutions-oriented teaching of wicked problems. Solutions-oriented teaching will help learners consider ways to address these issues, and may empower them while also reducing some anxiety and depression.

This paper outlines an innovative approach to using well-established active learning strategies simultaneously to encourage students to be solutions-oriented in the classroom. Traditionally, think-pair-share activities involve an opportunity for learners to independently consider the answer to a question, then share ideas with a colleague, before the discussion is presented to the larger group (Silberman, 1996), theoretically creating an environment where learners are more comfortable and prepared to contribute in large group settings. Dotmocracy is a form of cumulative voting that allows students to vote for their favourite ideas by way of stickers on chart-paper (Diceman, 2010). Finally, personal reflections are short free-writing exercises that encourage students to consider their personal and professional connection to the material or lesson, completed either in-class or after class (Silberman, 1996). 
The case study for this activity was a third-year Bachelor of Health Science and Bachelor of Public Health course on the Ecological Determinants of Health, designed following a recommendation from the Working Group on the Ecological Determinants of Health in Canada (Hancock, Spady, \& Soskolne, 2016). The class consisted of 170 students. The activities (think-pair-share, dotmocracy, and personal reflections) were amalgamated into a large multi-phase activity (Figure 1). The first phase of the activity began with a broad question: What can you do to protect the environment? Students were given a few minutes to think about the question alone and were encouraged to write a list of ideas they had come up with. Next, students shared their ideas with a person sitting nearby. With this person, they were encouraged to broaden their scope to actions that other stakeholders could implement to protect the environment. After approximately 5 minutes working in pairs, students were given instructions for phase 3. Phase 3 of the activity involved students moving around the classroom to record their ideas on large flip-chart papers under headings for the various stakeholders involved in the issue. Students were encouraged to write, sketch, or depict their ideas in any way they felt comfortable. Students were given approximately 10 minutes to record their ideas and generate additional ideas to answer the question. The next phase of the activity involved providing students with stickers to mark the ideas that they shared, the ideas they liked the best, or the ideas that inspired them. At this point students were asked to return to their seats and a brief group discussion facilitated by the instructor focused on key observations and messages ensued. Finally, students were given approximately 15 minutes to reflect on the lesson and the activities. Students were encouraged to write freely, focused on ideas rather than on spelling or grammar. Prompting questions for the reflection included: What were some of the most popular ideas? What inspired you? What, if anything, will you do differently because of this activity?

Journal of the Scholarship of Teaching and Learning, Vol. 20, No. 1, April 2020.

josotl.indiana.edu 


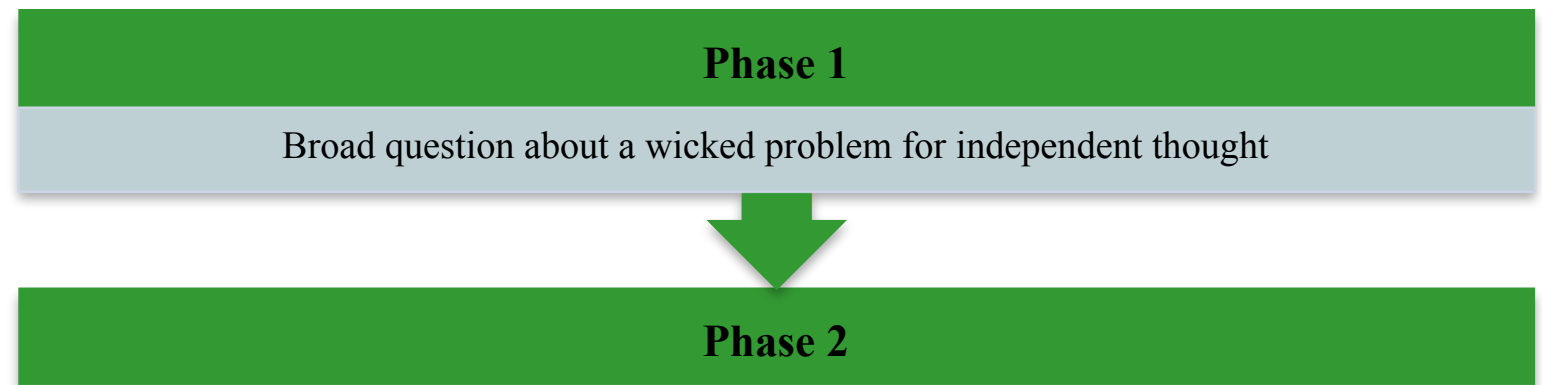

Partner idea sharing and redefining the scope of the problem and stakeholders

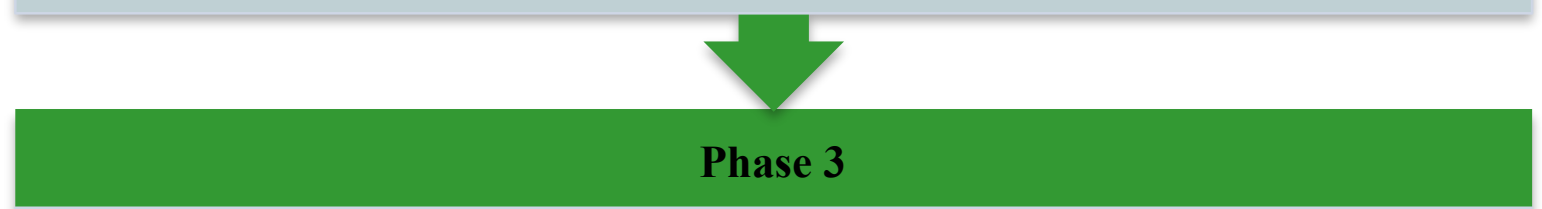

Creatively sharing ideas for solutions on flip-chart paper

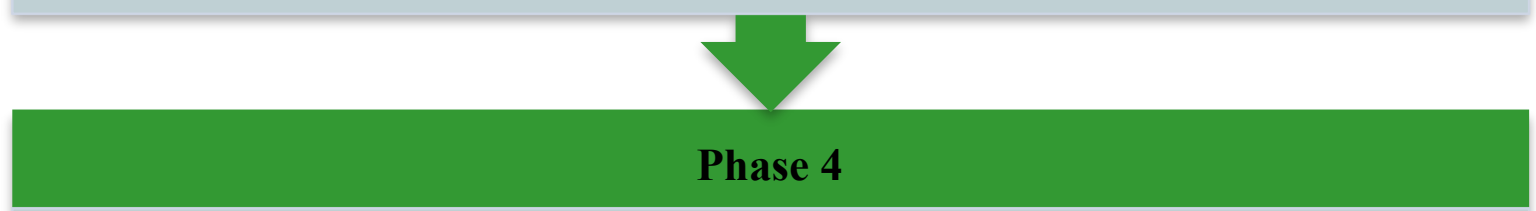

Dotmocracy of ideas depicted on flip-chart papers

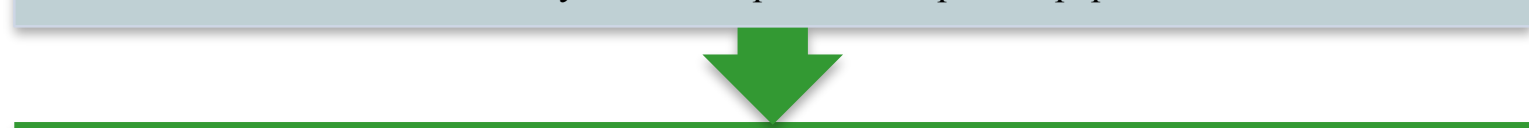

\section{Phase 5}

Group discussion of key observations and themes of solutions facilitated by instructor

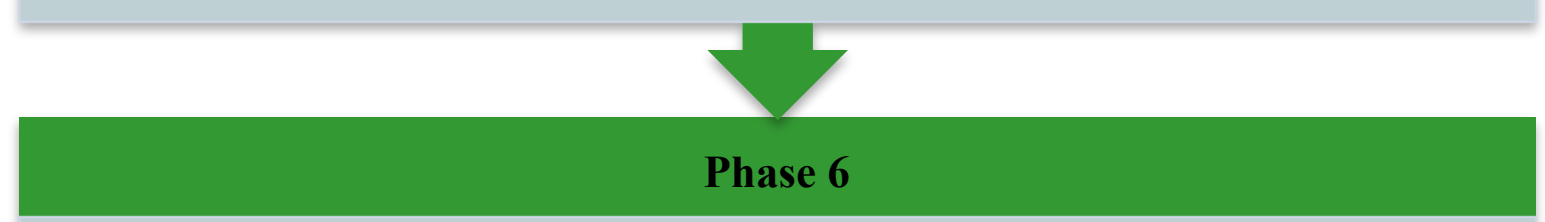

Personal reflection on learning and individual involvement in solutions

Figure 1. Step-by-step activity guide. Flow chart depicts the process for a multi-phase solutions-oriented teaching activity incorporating elements of think-pair-share, dotmocracy, and personal reflection.

A number of materials are needed for this activity. Educators will need flip-chart paper, tape, markers, and sticker dots. Students should come prepared with a pen and paper or a device that they can record their reflections on. Finally, the classroom must allow for students to move freely around the room. The case study class was held in a large lecture hall with row desks; however, sufficient aisle space made for a successful activity.

When reflecting on the lessons they had learned during the class, many students commented on the activity as well. The ideas expressed in the feedback are represented in a word-cloud (Figure 2). Key themes illustrated in the word-cloud include enjoyment, inspiration, engagement, interactive, and perspectives. Further, one student said: 
"It was inspiring to see my fellow peers contributing to this brainstorming/ ideaspreading process! It was a nice reminder that despite the dread (perhaps angst, even) I feel in regards to climate change, there are people willing to be more eco-friendly in their own lives."

Both the word-cloud and student comment suggest that the solutions-oriented nature of the activity and lesson helped to empower students in recognizing their potential and their power to contribute towards wicked problems like climate change.

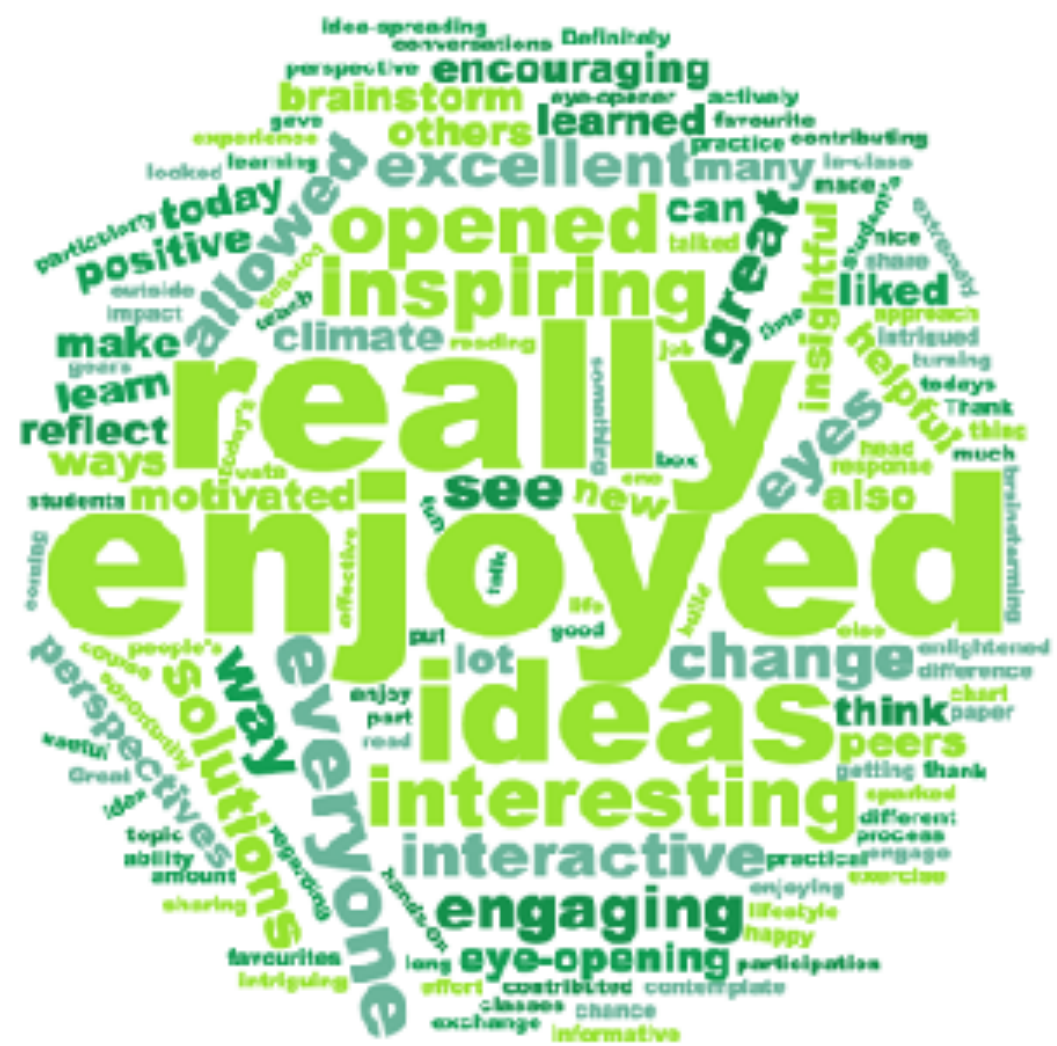

Figure 2. Evidence of student learning. Word cloud illustrating common themes of the feedback on the multi-phase activity used in class.

The activity presented some challenges that could be addressed in the future. The class size was large (170 students), which sometimes limited access to the flip-chart papers. Potential solutions could include dividing the class into groups and having them move around the flip-chart papers as stations, reducing crowding at a single topic. One student suggested that free software such as "Google Docs" could also be considered as a solution to the crowding issue; however, this would limit student discussions as they move around the room. Weighing the pros and cons of digitizing this activity should be a part of the implementation process for instructors.

The problems that face tomorrow's graduates are large, complex, and sometimes, truly wicked. It is essential that students be prepared to tackle these problems. Further, it is important that students recognize there are solutions to these problems and that their

Journal of the Scholarship of Teaching and Learning, Vol. 20, No. 1, April 2020.

josotl.indiana.edu 
colleagues and peers may be actively engaging in answering these questions with them. By providing solutions-oriented lessons and activities, educators can encourage, motivate, and inspire their students to be the global leaders our world needs.

\section{Acknowledgments}

Thank you to Kaitlin Roke for her constructive feedback on earlier drafts of this manuscript.

\section{References}

Costello, A., Abbas, M., Allen, A., Ball, S., Bell, S., Bellamy, R., . . Kett, M. (2009). Managing the health effects of climate change: Lancet and University College London Institute for Global Health Commission. The Lancet, 373(9676), 1693-1733. DOI: https:/ / doi.org/10.1016/S0140-6736(09)60935-1

Diceman, J. (2010). Dotmocracy handbook, version 2.2. In: Sur Internet: $<\underline{\text { http:// }}$ www.dotmocracy.org.

Hancock, T., Spady, D. W., \& Soskolne, C. L. (2016). Global change and public health: addressing the ecological determinants of health: Canadian Public Health Association.

Maxwell, J., \& Blashki, G. (2016). Teaching about climate change in medical education: an opportunity. Journal of public health research, 5(1). DOI: https://10.4081/jphr.2016.673

Silberman, M. (1996). Active Learning: 101 Strategies To Teach Any Subject. ERIC.

Waltner-Toews, D. (2017). Zoonoses, One Health and complexity: wicked problems and constructive conflict. Philosophical Transactions of the Royal Society B, 372(1725), 20160171. DOI: https://10.1098/rstb.2016.0171

Watts, N., Adger, W. N., Agnolucci, P., Blackstock, J., Byass, P., Cai, W., . . Cooper, A. (2015). Health and climate change: policy responses to protect public health. The Lancet, 386(10006), 1861-1914. 